\title{
Zooplankton Community Metrics as Indicators of Eutrophication in Urban Lakes
}

\author{
Sara Lodi ${ }^{1}$, Ludgero Cardoso Galli Vieira ${ }^{2}$, Luiz Felipe Machado Velho ${ }^{3}$, \\ Cláudia Costa Bonecker ${ }^{3}$, Priscilla de Carvalho ${ }^{4}$ \& Luis Mauricio Bini ${ }^{1, *}$
}

\author{
${ }^{1}$ Departamento de Ecologia, Universidade Federal de Goiás - UFG, Goiânia, Goiás, Brazil \\ ${ }^{2}$ Universidade de Brasília - UnB, Campus de Planaltina, DF, Brazil \\ ${ }^{3}$ Universidade Estadual de Maringá - UEM, Maringá, Paraná, Brazil \\ ${ }^{4}$ Life Projetos Limnológicos, Goiânia, Goiás, Brazil
}

\begin{abstract}
Although the direct effects of eutrophication are well known, its indirect effects are poorly understood and the interaction with non-nutrient factors may alter some expected relationships. We analyzed the reliability of community-level metrics derived from three zooplankton groups as predictors of eutrophication in urban man-made lakes. Univariate and multivariate correlation analyses were used to test for relationships between environmental variables and community metrics derived from zooplankton data. Our results indicated that rotifer community metrics were the best eutrophication indicators. The main implication of our results is that arguments against the use of simple community-level metrics as indicators of eutrophication cannot be generalized. Our findings also suggest the need of complete sample analyses (i.e., identification and counting) to estimate reliable ecological indicators of eutrophication.
\end{abstract}

Key words: Species Richness, Evenness, Zooplankton, Eutrophication, Biomonitoring.

\section{Introduction}

Large nutrient inputs, especially of nitrogen $(\mathrm{N})$ and phosphorous $(\mathrm{P})$, are expected in either natural or man-made water bodies in urban areas. In general, these inputs are the most responsible for eutrophication (Vollenweider 1968; Schindler 2006 and references therein). During the eutrophication process, there is an increase in the availability and in the rate of nutrient utilization by primary producers, resulting in environments with high biomass (Schneider \& Melzer 2003). In addition, biodiversity losses, as indicated by species richness or other measures (see Magurran 2004) are also expected (Camargo et al. 2005; Jeppesen et al. 2000). Thus, eutrophication may have a cascading effect on different trophic levels and, especially, in zooplankton communities (e.g., Ravera 1980). For instance, frequent algae blooms may cause a decline of submerged aquatic vegetation and without the refuge promoted by these plants, there is an increased rate of predation by zooplanktivorous fish. As a net result, the process of

*Send correspondence to: Luis Mauricio Bini Departamento de Ecologia,

Instituto de Ciências Biologicas - ICB,

Universidade Federal de Goiás - UFG,

CP 131, CEP 74001-970, Goiânia, GO, Brasil

E-mail: lmbini@gmail.com eutrophication can even be accelerated due to the lowering of zooplankton grazing rates (Scheffer et al. 1993). Also, in eutrophic environments, phytoplankton communities are often dominated by Cyanophyceae (Reynolds et al. 2002). Thus, besides the indirect effects of the absence of refuge offered by submerged aquatic vegetation, zooplankton communities may be directly affected by eutrophication as a result of the increased density of inedible and toxin producing species (Auer et al. 2004; Schindler \& Hecky 2009). As not all herbivorous species are able to maintain viable populations under these conditions, monopolies of a few zooplankton species are also expected.

Different zooplankton groups may have contrasting responses to eutrophication due to, among other factors, differences in reproductive rates (Fileto et al. 2004), filtering capacities (Xie et al. 1998) and specializations in acquiring food (Schriver et al. 1995). Besides, in monitoring studies, different population and community metrics or variates (e.g., density, biomass, species richness, evenness, and diversity of specific groups) may be used as ecological indicators to evaluate the effects of eutrophication or the efficiency of a control program. However, it is important to note that the choice of a metric should be based on different issues 
as, for instance, its reliability as an ecological indicator (see Cottingham \& Carpenter 1998 for a discussion based on phytoplankton), the availability of taxonomists, the spatial extent that can be covered (e.g., number of lakes) and the sampling frequency of the monitoring program. For example, depending on the sampling frequency or the number of lakes that should be monitored, the use of a more time-consuming metric may be prohibitive.

In Brazil (and possibly in other developing countries), most monitoring programs on eutrophication are based on specific group of organisms, which are selected, in general, by the availability of taxonomists. The reliability of the chosen group as a meaningful ecological indicator is, however, rarely tested and the capabilities of this group in predicting the responses of other taxa to eutrophication are, at best, only supposed. The search for a reliable taxonomic group and an associated metric is not a trivial issue because a number of factors (e.g., ecosystem type, size, species composition of other groups, and climate conditions) interact to generate the response of a given group to the environmental process under study.

In this context, our goal was to test the reliability of community-level metrics (species richness, evenness, total density), derived from three zooplankton groups (testate amoebae, microcrustaceans and rotifers), in predicting the level of eutrophication of urban man-made lakes. Our aim was to verify which group and metric should be used as a surrogate (or as a complement) for chemical analyses (e.g., nutrient and chlorophyll- $a$ concentrations), which are not always feasible in developing countries due to the lack of resources and expertise.

\section{Methods}

The city of Goiânia ( $16^{\circ} 40^{\prime} \mathrm{S}$ and $49^{\circ} 15^{\prime} \mathrm{W}$; Goiás State, Brazil), where this study was conducted, is known to have several artificial lakes that were created for landscaping and recreational purposes. From these, we sampled 11 artificial lakes (located at six streams) distributed in eight municipal parks: Buriti Forest, Chico Mendes Botanical Garden and Flamboyant, each one with two lakes, and Areião, Beija-Flor, Botafogo, Sullivan Silvestre and Liberdade, each one with a lake. Lake area ranged from 1.76 to $29.2 \mathrm{~km}^{2}$, and maximum depth from 0.75 to $2.75 \mathrm{~m}$ (see Table S1 in the supplementary material).

Sampling was carried out in October 2008. We measured four environmental variables that are tightly related to the process of eutrophication. Water transparency was determined with a $30 \mathrm{~cm}$ Secchi disk. Water samples, gathered from the central region of each lake, were analyzed for chlorophyll- $a$, total Kjeldahl nitrogen (TKN) and total phosphorus (P) according to APHA (2005).

For zooplankton samples, we used a water pump to filter ca. $500 \mathrm{~L}$ of water through a $64-\mu \mathrm{m}$ plankton net. The filtered material was fixed in a $4 \%$ formaldehyde solution, buffered with calcium carbonate. Samples were examined microscopically in Sedgwick-Rafter chambers for species identification (to the lowest possible taxonomic level) and counting of microcrustaceans, rotifers and testate amoebae (see supplementary material for the taxonomic literature used). Counting was undertaken by the analysis of tree subsamples obtained with a Hensen-Stempel pipette (3 mL). At least 100 individuals per subsample were counted (Bottrell et al. 1976). A qualitative analysis was also carried out to record rare species. To this end, subsequent sub-samples were analyzed, in each sample, until no new species were recorded.

Spearman's correlation analyses were used to test for relationships between environmental variables (water transparency, total phosphorus, TKN and chlorophyll-a) and the following metrics derived from zooplankton data: total density, species richness and evenness (J') (Magurran 2004). In order to control for increased type I error rates due to multiple testing, the False Discovery Rate (FDR) method was applied (Benjamini \& Hochberg 1995; García 2004).

We also performed a Canonical Correlation Analysis (CCorA) (Legendre \& Legendre 1998) in order to test for significant multivariate relationships between the three metrics (density, richness and evenness) and the four correlates of eutrophication (water transparency, total phosphorus, TKN and chlorophyll- $a$ ). We performed an independent CCorA for each zooplankton group. To explore the potential of species composition in indicating eutrophication levels, we first classified the lakes into three trophic states (oligotrophic, mesotrophic and eutrophic) according to chlorophyll- $a$ concentrations (following Carlson 1977). Subsequently, we used a multiple response permutation procedure (MRPP) (Biondini et al. 1988) to test the hypothesis that species composition did not differ among trophic states.

Results from these analyses may offer support to four general scenarios in terms of optimizing biomonitoring studies (see Heino \& Soininen 2010 for a similar reasoning in the context of common species sufficiency in describing turnover in aquatic communities): 1) total density (or total density of a particular zooplankton group) is highly and significantly correlated with the environmental variables; in this case, biomonitoring could only rely on the estimation of density and species identification would be nonessential; 2) we can assume that the main predictor of eutrophication is species richness (total or of a given zooplankton group); thus, a species list per site would be necessary; 3 ) the effects of eutrophication can be detected only by using species composition data; thus, the analyses of the samples should generate, at least, a species presence/absence data table; and 4) finally, evenness can be the best indicator of eutrophication and, in that case, complete analyses of the samples (i.e., counting and identification) would be necessary. We assume that time to process the samples increases progressively from scenario one to four. 


\section{Results}

Environmental data varied greatly among lakes, indicating a range of trophic states (Carlson 1997). For instance, trophic states varied from oligotrophic to eutrophic, according to chlorophyll- $a$ concentrations (i.e., from values below the detection limit to $12.6 \mu \mathrm{g} . \mathrm{L}^{-1}$ ), from eutrophic to hypereutrophic, according to Secchi depth (ranging from 21 to $150 \mathrm{~cm}$ ), and from mesotrophic to eutrophic, according to total phosphorus concentrations (16.9 to $85.7 \mu \mathrm{g} . \mathrm{L}^{-1}$ ) (Table S1 in the Additional Supporting Information at www.abecol.org.br). Both total Kjeldahl nitrogen and total phosphorus concentrations were significantly correlated with chlorophyll- $a$ concentration (Spearman's correlations $=0.69$ and $0.70, P$-values $=0.018$ and 0.016 , respectively) .

Sixty-nine taxa were recorded across the eleven lakes and rotifers were the most species rich group (37 taxa), followed by testate amoebae (21) and microcrustaceans (11). Local species richness ranged from 12 to 29 species (Figure 1). Nauplii dominated the zooplankton community in four lakes (lakes 1, 2, 7 and 9 - see Table S1 for codes), while Bosmina hagmanni was the most abundant species in lakes 3 and 11, and was the second most abundant species in lakes 4, 5, 8 and 9. Zooplankton communities from lakes 4 and 5 were dominated by Brachionus falcatus and Brachionus angularis, respectively. Keratella cochlearis dominated the zooplankton communities of lakes 6 and 10, while copepodites were dominant in lake 8 . On average, lakes dominated by microcrustaceans contained lower concentrations of chlorophyll-a $\left(3.3 \mu \mathrm{g} . \mathrm{L}^{-1}\right)$ than lakes dominated by rotifers $\left(9.5 \mu \mathrm{g} . \mathrm{L}^{-1}\right)$ (see Table S1 and Figure 2).

According to the FDR criterion, total density was significantly and negatively correlated with water transparency and positively correlated with total phosphorus. Evenness,

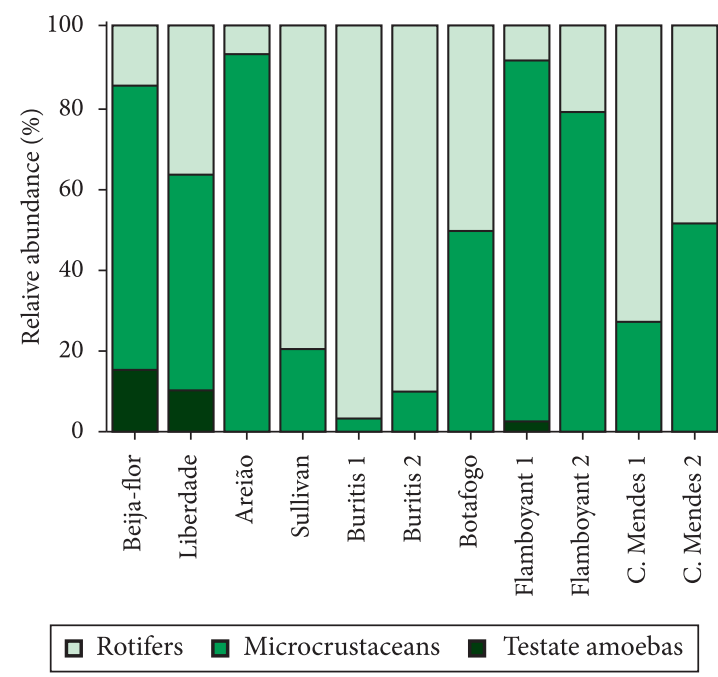

Figure 2. Relative abundance (\%) of the zooplankton groups for the eleven lakes studied.

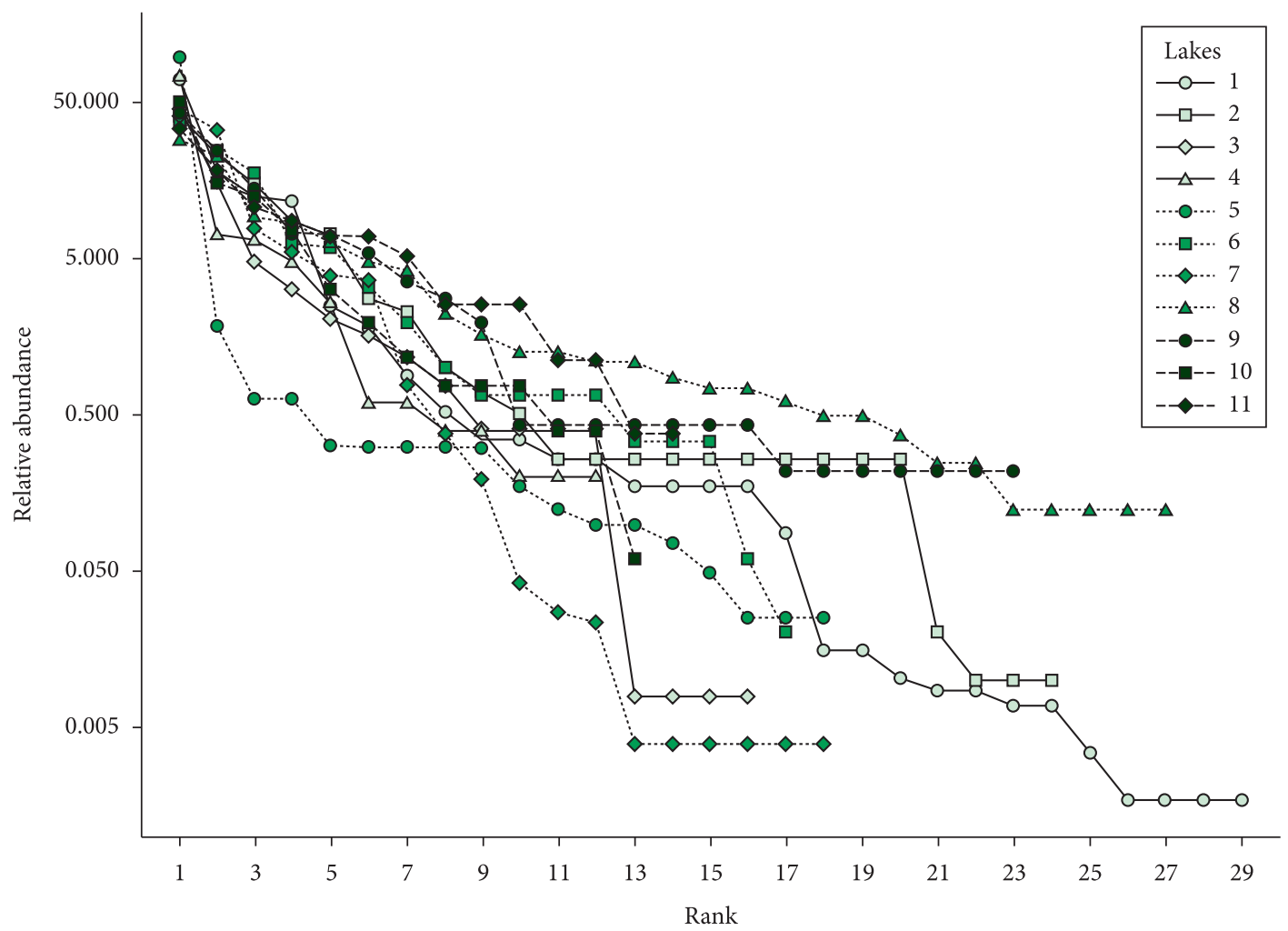

Figure 1. Rank-abundance plot of each lake. Taxa are ranked from most to least abundant. See Table S1 in the Additional Supporting Information at www.abecol.org.br, for lakes' codes. 
when calculated for the whole zooplankton community, was positively correlated with water transparency and negatively correlated with total Kjeldahl nitrogen (TKN) (Table S2).

Microcrustacean richness was negatively correlated with chlorophyll- $a$ concentration. Rotifer density and evenness were significantly correlated with all environmental variables. Thus, density increased with the decrease of water transparency and with the increase of nutrients and chlorophyll- $a$ concentrations. The signal of the correlations were inverted for evenness, in such way that lakes with high water transparencies and low nutrient and chlorophyll- $a$ concentrations tended to have high evenness. In general, the highest correlations were found for this group (Table S2).

Similar to the results of the univariate analyses, the correlation between the first pair of canonical variates was statistically significant only for rotifers (Table 1). For this group, according to the redundancy coefficients, the first pair of canonical variates extracted $77.2 \%$ of the variance from the four environmental variables and $66.7 \%$ of the variance from the metrics. More equitable and species rich rotifer

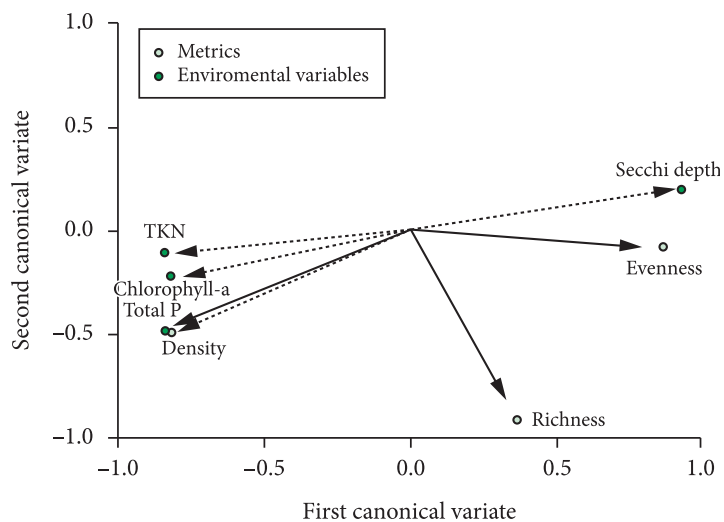

Figure 3. Pearson's correlations between the variables and canonical variates. The two sets of variables used in the Canonical Correlation Analysis are differentiated by using two styles of arrows (continuous: community metrics; dashed: environmental variables) communities were found in lakes with clear waters and low nutrient and chlorophyll- $a$ concentrations (Figure 3 ).

For the whole community and for each one of the taxonomic groups, MRPP indicated that there were no statistical differences in species composition among the groups of lakes classified according to trophic states ( $A$ values ranging from -0.01 to 0.04 and $P$-values $>0.10$ in all cases).

\section{Discussion}

Considering that eutrophication interacts with many lake-specific conditions (Sarnelle et al. 2010; Smith \& Schindler 2009), the search for reliable indicators of this process should be done in a case-by-case basis. Our results, when compared to others, clearly highlight this point. Here, we found that total density and evenness of rotifer communities were the best correlates of eutrophication. On the other hand, some studies have pointed out that diversity indices were, in general, poor indicators of eutrophication effects on the structure of zooplankton communities (Attayde \& Bozelli 1998; Baião \& Boavida 2005). Our results do, however, agree with those of Dodson et al. (2000), who also found a negative relationship between crustacean species richness and eutrophication level. Like Dodson et al. (2000), we found no significant relationship between this process and rotifer species richness (see also Rublee \& Bettez 1995; Jeppesen et al. 2000). Despite the general statement made by Attayde \& Bozelli (1998), that diversity indexes were poor predictors of eutrophication, like us, they found that total zooplankton density increased with eutrophication level. As a last example, similar to our results, microcrustacean species richness in Danish lakes declined conspicuously with increasing total phosphorus concentration (Jeppesen et al. 2000).

At least in Brazil, there is a tendency to use testate amoebae in biomonitoring studies (e.g. Lansac-Tôha et al. 2009). However, our results indicate that this group is a poor indicator of eutrophication (but see Branco et al. 2002; Nishibe et al. 2004). The inclusion of this group in biomonitoring programs is, probably, only justified to evaluate the impacts derived from hydrological changes caused by river damming (Lansac-Tôha et al. 2009).

Table 1. Canonical correlations $(R)$, chi-square $\left(\chi^{2}\right)$ values and significance levels $(P)$ of the first three canonical variates $(C V)$ extracted from analyses relating environmental variables and zooplankton community-level metrics.

\begin{tabular}{lccrc}
\hline \multicolumn{1}{c}{ Group } & CV & $R$ & $\chi^{2}$ & $P$ \\
\hline Testate amoebae & CV 1 & 0.90 & 13.05 & 0.365 \\
& CV 2 & 0.55 & 2.80 & 0.833 \\
& CV 3 & 0.31 & 0.62 & 0.733 \\
\hline Microcrustaceans & CV 1 & 0.83 & 12.94 & 0.374 \\
& CV 2 & 0.77 & 5.96 & 0.427 \\
\hline Rotifers & CV 3 & 0.30 & 0.57 & 0.751 \\
& CV 1 & 0.97 & 21.50 & 0.044 \\
& CV 2 & 0.67 & 4.28 & 0.638 \\
\hline
\end{tabular}


There is a general expectation that species composition data tend to be more responsive to different perturbations than aggregate variates (Cottingham \& Carpenter 1998 and references therein). Aggregate variates (e.g., total density) are supposed to be poor ecological indicators because, for example, compensatory dynamics may mask the effects of the perturbation under study (Attayde \& Bozelli 1998). Similarly to most of the studies cited above, our results suggest the opposite as MRPP analyses indicated no difference in species composition among the lakes grouped in different trophic states. We emphasize, in addition, that our gradient of phytoplankton biomass was relatively short (from 0.0 to $12.6 \mu \mathrm{g} . \mathrm{L}^{-1}$ ) and, even so, we detected strong relationships among aggregate variates and eutrophication, in the directions expected for this process. This is particularly important to validate the use of ecological indicators because indicators responding only after high levels of eutrophication can be considered ineffective.

Although our results suggest that aggregate variates or community-level metrics may be used as reliable ecological indicators of eutrophication, they also indicate that there is little room for optimizing biomonitoring studies. Thus, we argue that a complete analysis of the samples (i.e., counting and identification; the fourth scenario; see above) is necessary to monitor the effects of eutrophication. In terms of taxonomic range, our results suggest that analyses based on the rotifer community would be sufficient.

Our results indicate that total density and evenness of rotifer were reliable ecological indicators of eutrophication and that arguments against the use of simple community-level metrics cannot be generalized. There is little hope for the use of simple metrics (e.g., total density or species richness) that can be estimated without complete analyses of the samples (i.e., identification and counting).

\section{Acknowledgements}

Brazilian funding agencies (CNPq, CAPES and FUNAPE) have continuously supported our work.

\section{References}

APHA - American Public Health Association, 2005. Standard methods for the examination of water and wasterwater. Washington: Byrd Prepress Springfield.

Attayde JL \& Bozelli RL, 1998. Assessing the indicator properties of zooplankton assemblages to disturbance gradients by canonical correspondence analysis. Canadian Journal of Fisheries and Aquatic Science, 55:1789-1797. http://dx.doi. org/10.1139/f98-033

Auer B, Elzer U \& Arndt H, 2004. Comparison of pelagic food webs in lakes along a trophic gradient and with seasonal aspects: influence of resource and predation. Journal of Plankton Research, 26:697-709. http://dx.doi.org/10.1093/ plankt/fbh058
Baião C \& Boavida MJ, 2005. Rotifers of Portuguese reservoirs in river Tejo catchment: Relations with trophic state. Limnetica, 24:103-114.

Benjamini Y \& Hochberg Y, 1995. Controlling the False Discovery Rate - A Practical and Powerful Approach to Multiple Testing. Journal of the Royal Statistical Society Series B-Methodological, 57:289-300.

Biondini ME, Redente EF \& Mielke PW, 1988. Permutation techniques based on Euclidean analysis spaces: a new and powerful statistical method for ecological research. Coenoses, 3:155-174.

Bottrell HH et al.,1976. Review of Some Problems in Zooplankton Production Studies. Norwegian Journal of Zoology, 24:419-456.

Branco CWC et al., 2002. Limnological features of Funil Reservoir (R.J., Brazil) and indicator properties of rotifers and cladocerans of the zooplankton community. Lakes \& Reservoirs: Research and Management, 7: 87-92. http:// dx.doi.org/10.1046/j.1440-169X.2002.00177.x

Camargo JA, Alonso K \& de la Puente M, 2005. Eutrophication downstream from small reservoirs in mountain rivers of Central Spain. Water Research, 39:3376-3384. http://dx.doi. org/10.1016/j.watres.2005.05.048

Carlson RE, 1977. Trophic State Index for Lakes. Limnology and Oceanography, 22:361-369. http://dx.doi.org/10.4319/ lo.1977.22.2.0361

Cottingham KL \& Carpenter SR, 1998. Population, community, and ecosystem variates as ecological indicators: Phytoplankton responses to whole-lake enrichment. Ecological Applications, 8:508-530. http:// dx.doi.org/10.1890/1051-0761(1998)008[0508:PCAEVA ]2.0. $\mathrm{CO} ; 2$

Dodson SI, Arnott SE \& Cottingham KL, 2000. The relationship in lake communities between primary productivity and species richness. Ecology, 81:2662-2679. http://dx.doi. org/10.1890/0012-9658(2000)081[2662:TRILCB]2.0.CO;2

Fileto C et al., 2004. Influence of phytoplankton fractions on growth and reproduction of tropical cladocerans. Aquatic Ecology, 38: 503-514. http://dx.doi.org/10.1007/ s10452-004-4087-x

García LV, 2004. Escaping the Bonferroni iron claw in ecological studies. Oikos, 105:657.663.

Heino J \& Soininen J, 2010. Are common species sufficient in describing turnover in aquatic metacommunities along environmental and spatial gradients? Limnology and Oceanography, 55:2397-2402. http://dx.doi.org/10.4319/ lo.2010.55.6.2397

Jeppesen et al., 2000. Trophic structure, species richness and biodiversity in Danish lakes: changes along a phosphorus gradient. Freshwater Biology, 45:201-218. http://dx.doi. org/10.1046/j.1365-2427.2000.00675.x

Lansac-Tôha FA et al., 2009. Biodiversity of zooplankton communities in the Upper Parana River floodplain: interannual variation from long-term studies. Brazilian Journal of Biology, 69:539-549. http://dx.doi.org/10.1590/ S1519-69842009000300009 
Legendre P \& Legendre L, 1998. Numerical Ecology. Amsterdan: Elsevier.

Magurran AE, 2004. Mesuring biological diversity. Oxford: Blackwell Science Ltd.

Nishibe Y et al., 2004. Trophic coupling of a testate amoeba and Microcystis species in a hypertrophic pond. Limnology, 5:71-76. http://dx.doi.org/10.1007/ s10201-004-0114-9

Ravera O, 1980. Effects of Eutrophication on Zooplankton. Progress in Water Technology, 12:141-159.

Reynolds CS et al., 2002. Towards a functional classification of the freshwater phytoplankton. Journal of Plankton Research, 24:417-428. http://dx.doi.org/10.1093/ plankt/24.5.417

Rublee PA \& Bettez N, 1995. Change of microplankton community structure in response to fertilization of an arctic lake. Hydrobiologia, 312:183-190. http://dx.doi. org/10.1007/BF00015511

Sarnelle O et al., 2010. Citizen monitoring: Testing hypotheses about the interactive influences of eutrophication and mussel invasion on a cyanobacterial toxin in lakes. Water Research, 44:141-150. PMid:19781732. http://dx.doi. org/10.1016/j.watres.2009.09.014

Scheffer M et al., 1993. Alternative Equilibria in Shallow Lakes. Trends in Ecology \& Evolution, 8:275-279. http://dx.doi. org/10.1016/0169-5347(93)90254-M
Schindler DW \& Hecky RE, 2009. Eutrophication: More Nitrogen Data Needed. Science, 324:721-722. PMid:19423798. http:// dx.doi.org/10.1126/science.324_721b

Schindler DW, 2006. Recent advances in the understanding and management of eutrophication. Limnology and Oceanography, 51:356-363. http://dx.doi.org/10.4319/ lo.2006.51.1_part_2.0356

Schneider S \& Melzer A, 2003. The trophic index of macrophytes (TIM) - a new tool for indicating the trophic state of running waters. International Review of Hydrobiology, 88: 49-67. http://dx.doi.org/10.1002/iroh.200390005

Schriver P et al., 1995. Impact of Submerged Macrophytes on Fish-Zooplankton-Phytoplankton Interactions - LargeScale Enclosure Experiments in A Shallow Eutrophic Lake. Freshwater Biology, 33: 255-270. http://dx.doi. org/10.1111/j.1365-2427.1995.tb01166.x

Smith VH \& Schindler DW, 2009. Eutrophication science: where do we go from here? Trends in Ecology \& Evolution, 24:201-207.

Vollenweider RA, 1968. Scientific fundamentals of the eutrophication of lakes and flowing waters, with particular reference to nitrogen and phosphorus as factors in eutrophication. Paris: Organisation for Economic Co-operation and Developmen. Tech. Rpt. DA 5/SCI/68.27, -250. OECD. http://dx.doi.org/10.1016/j.tree.2008.11.009

Xie P, Iwakuma T \& Fujii K, 1998. Changes in the structure of a zooplankton community during a Ceratium (dinoflagellate) bloom in a eutrophic fishless pond. Journal of Plankton Research, 20:1663-1678. http://dx.doi.org/10.1093/ plankt/20.9.1663

Received: May 2011

First Decision: May 2011

Accepted: May 2011 